\title{
Reflexo de grandes eventos na mobilidade urbana
}

\author{
Impact of great events on urban mobility
}

\begin{abstract}
Daniel de Oliveira Mota[a] $([$, Bernardo Brasil Garcia Rodrigues dos Santos $[$ [b] $([)$, Nicoli Ramos Cardoso[b] ㄱ, Victor Pirinausky[b] $@$, Guilherme dos Santos Musich[b]
\end{abstract}

[a] Universidade de São Paulo (USP), Departamento de Engenharia de Produção, São Paulo, SP, Brasil

[b] Instituto Mauá de Tecnologia (IMT), Departamento de Engenharia de Produção, São Caetano do Sul, SP, Brasil

Como citar: Mota, D. O., Santos, B. B. G. R., Cardoso, N. R., Pirinausky, V., \& Musich, G. S. (2020). Reflexo de grandes eventos na mobilidade urbana. urbe. Revista Brasileira de Gestão Urbana, 12, e20190363. https://doi.org/10.1590/21753369.012.e20190363

\section{Resumo}

A mobilidade em megacidades tem se tornado um problema relevante para todos que transitam em regiões de intenso tráfego de veículos e pessoas. Este problema é agravado durante a ocorrência de grandes eventos, como partidas esportivas, feiras e concertos musicais que atraem uma elevada audiência. Neste contexto, o Allianz Parque é um importante local que oferece eventos no Brasil, ao mesmo tempo em que é uma região onde se observa um elevado tráfego urbano. Para se obter dados do fluxo de pedestres e, ao mesmo tempo, de veículos do transporte público na região, ferramentas de Big Data foram empregadas a partir das redes sociais, capturando informações de localização geográfica, instante das postagens e posições dos veículos disponibilizados publicamente. Em seguida, alguns indicadores de desempenho foram criados para quantificar a intensidade e persistência do impacto na mobilidade durante os eventos, comparando seus padrões com os dos dias regulares. Esta análise evidenciou que existe uma interferência durante a ocorrência dos eventos tanto na mobilidade quanto no acesso aos locais. Este impacto varia de acordo com o evento (público, faixa etária, tipo), podendo se caracterizar tanto em termos de intensidade quanto em termos de persistência.

Palavras-chave: Mobilidade urbana. Eventos. Rede social. Transporte. Ônibus.

\section{Abstract}

Mobility in megacities has become a relevant problem for everyone who transits in regions of intense traffic of vehicles and people. This problem is aggravated during occurrences of major entertainment events, such as sport matches, fairs and musical concerts, which attract a large audience. In the current context, Allianz Park is an important place for holding events in Brazil, whereas it is in a region where there is intense urban traffic. To obtain pedestrian flow data and public transport vehicles in the region, big data analytics tools were used to collect information from a social network. Those big analytics tools captured the

DOM é engenheiro de Produção, doutor, professor, e-mail: danielmota@usp.br

BBGRS é engenheiro de Produção, bacharel, e-mail: bernardobrasil.grsantos@gmail.com

NRC é engenheiro de Produção, bacharel, e-mail: nicoliramos222@hotmail.com

VP é engenheiro de Produção, bacharel, e-mail: pirinausky@gmail.com

GSM é engenheiro de Produção, bacharel, e-mail: guimusich@hotmail.com 
information of geographical location and time of publications and public transportation authority, collecting data of public transportation with the geographical positions associated with the pedestrian. Therefore, some indicators were created to quantify the intensity and persistence of the impact on the mobility of days with events, when compared with the standard pattern of speed of public transport in regular days. This analysis expresses that there is a typical pattern of interference in the urban mobility of the study region during events, with a variation according to some specific factors of the comparison event. Thus, it was identified characteristics of the events in terms of intensity and persistence.

Keywords: Urban mobility. Events. Social networks. Transport. Bus.

\section{Introdução}

0 trânsito em megacidades é um problema que atinge grande parte dos seus habitantes. Na cidade de São Paulo, por exemplo, aproximadamente $40 \%$ dos cidadãos gasta mais de duas horas por dia em seus deslocamentos devido ao trânsito. Pelo fato de o número de veículos no Brasil ser de aproximadamente 73 milhões, este efeito é agravado. Segundo noticiários locais, na cidade de São Paulo, 64\% dos automóveis particulares são utilizados por apenas uma pessoa e existem estudos que relacionam o tamanho da frota com o tempo médio gasto pelos cidadãos no trânsito.

O transtorno ocasionado pelo longo período de circulação de automóveis causa prejuízo econômico para a cidade. Este prejuízo, estimado em trinta bilhões de reais anuais, correspondente a aproximadamente 7,5\% do PIB paulistano e origina-se do tempo gasto pela população no trânsito que poderia ser revertido em horas de trabalho, aumentando a produtividade dos colaboradores em São Paulo.

Outro fator impactante no trânsito é a quantidade de veículos coletivos nas ruas. Com o passar dos anos, a quantidade de ônibus em São Paulo aumentou consideravelmente e continua sendo o principal transporte público dos cidadãos na cidade. Pode-se observar, portanto, que a alternativa a esse meio de transporte é o transporte individual que tem se apresentado como uma das fontes geradoras de lentidão na cidade e influencia o fluxo do tráfego e o tempo gasto pelas pessoas. Desta forma, o transporte público deve ser melhor aproveitado dado seu importante fator de escala: cada ônibus transporta aproximadamente 75 passageiros, enquanto cada carro transporta um único passageiro.

A lentidão em uma megacidade pode ser causada por diversos motivos, dentre eles: (1) excesso de carros; (2) acidentes; (3) manutenção de vias; e (4) vias bloqueadas. Dado que São Paulo é a cidade mais populosa da América, o reflexo na mobilidade urbana pode ser agravado quando considerado o entorno de locais de grande concentração de pessoas.

A arena Allianz Parque, localizada na avenida Francisco Matarazzo 1705, região central de SP, é considerada a segunda com o maior número de shows e eventos do mundo. 0 estádio recebeu, nos dois primeiros anos de sua inauguração, 103 eventos culturais e profissionais, 67 jogos, 21 shows e, aproximadamente, 3 milhões de pessoas. Toda a movimentação descrita em virtude dos eventos é, geralmente, somada à movimentação cotidiana da região que conta com shoppings centers, escolas, prédios comerciais e terminais de transporte público (Figura 1).

Foram coletadas informações de latitude, longitude, data e hora do transporte público e das publicações em rede social, que são as variáveis em estudo adequadas para quantificar o problema em estudo. Portanto, o objetivo do presente trabalho é descrever e quantificar o impacto gerado por eventos no entorno de uma região com alto adensamento populacional. Eventos, como concertos musicais e partidas esportivas, foram estudados por meio da observação dos efeitos dinâmicos de dois importantes atores do ambiente urbano: aglomeração de pessoas e congestionamento de ônibus. Assim, foram comparadas as análises de efeitos em dias normais e dias de grandes eventos para, consequentemente, demonstrar o impacto resultante dos fenômenos.

Busca-se quantificar o impacto na mobilidade de uma região próxima ao local onde ocorre um grande evento. Não existe na literatura um indicador representativo da situação do trânsito durante ocorrências 
de alta circulação de pessoas e, em razão disso, as principais áreas afetadas sofrem negativamente o reflexo do evento na mobilidade de pessoas e no transporte público.

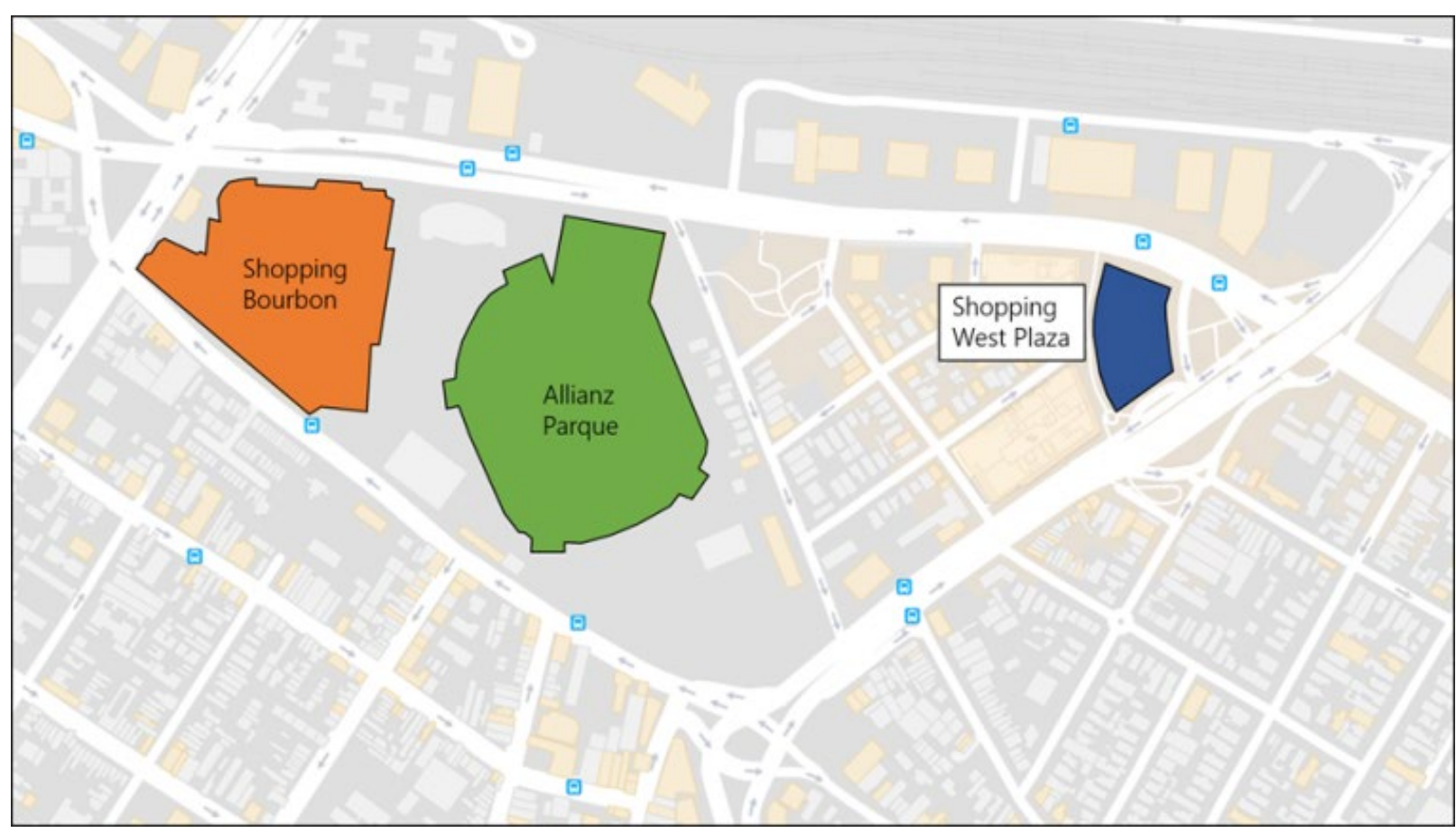

Figura 1 - Pontos críticos da região de estudo. Fonte: Os autores.

\section{Mobilidade urbana em megacidades}

Segundo Rau (2012), mobilidade urbana é definida como a capacidade da movimentação de pessoas e bens em um ambiente urbano, com a finalidade de atender as necessidades cotidianas de seus habitantes. Refletindo em uma nova análise da logística detalhada desses centros urbanos, o conceito pode ser aplicado ao estudo de todos os tipos de deslocamentos urbanos e expandido também pelo estudo da relação do atendimento das constantes necessidades da população com os meios que impactam positiva ou negativamente esses deslocamentos.

No cenário mundial recente, observa-se elevados níveis de urbanização e industrialização em comparação com séculos passados. A concentração das atividades econômicas mundiais em alguns polos específicos ao redor do mundo atraem pessoas em busca de novas oportunidades e melhor qualidade de vida devido ao desenvolvimento destas regiões. Neste contexto, surge o termo megacidade, que é utilizado para referenciar essas áreas metropolitanas que possuem mais de 10 milhões de habitantes e um rápido crescimento urbano, segundo Molina \& Molina (2004). Ainda segundo Rau (2012), aproximadamente $60 \%$ do produto interno bruto de um país é proveniente de áreas urbanas e, sendo assim, o resultado da aplicação desse desenvolvimento gera atrativos econômicos que, por consequência, resultam no crescimento urbano, aumentando o índice de imigração.

Para Leite (2017), as megacidades integram uma rede com grande densidade e movimentação de pessoas, atividades e negócios, podendo, portanto, determinar e ditar o rumo da civilização. Esta rede é formada por "40 mega regiões dos 191 países do mundo que impulsionam a economia mundial - elas representam $1 / 5$ da população, $2 / 3$ do rendimento econômico mundial e mais de $85 \%$ da inovação global" (Figura 2).

Com um rápido desenvolvimento, as megacidades sofrem problemas graves no planejamento urbano, que por sua vez, refletem no comprometimento da mobilidade urbana. Conforme apontam Mendonça \& Kneib (2016), esses impactos afetam a degradação do meio ambiente e a qualidade de vida da população 
devido à geração de congestionamentos e à dificuldade crescente no deslocamento diário pelos centros urbanos. Também são identificadas a concentração e existência de problemas socioambientais e de pobreza, além de logísticos, tornando-se uma preocupação constante do governo analisar novamente os conceitos e padrões das políticas urbanas aplicáveis, reforçando o pensamento de Reddy \& Balachandra (2010), que indicam o esforço das áreas urbanas de conseguir manter um alto nível de mobilidade. Os autores afirmam que essas megacidades só conseguem se sustentar se forem garantidas a manutenção e eficiência de todos os sistemas de transporte existentes.

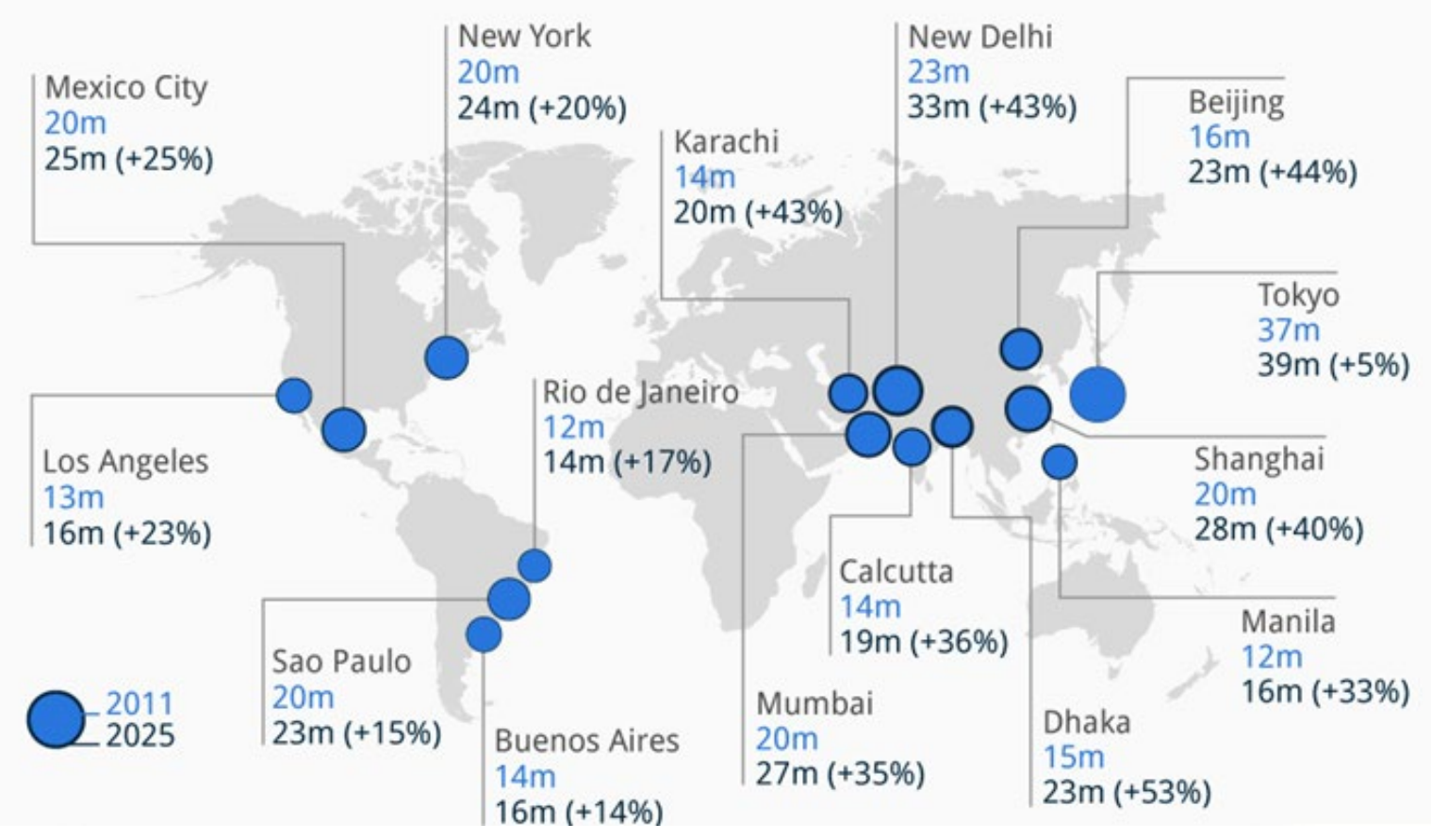

Figura 2 - As 15 maiores megacidades e suas previsões populacionais. Fonte: Statista, 2014.

Com o surgimento de novos desafios urbanos ocasionados pelo desenvolvimento acentuado das megacidades, há necessidade de expansão e atuação dos meios de transporte, atendendo à nova demanda gerada pelo aumento da concentração populacional local e da taxa de urbanização. 0 aumento constante da utilização de veículos automotores, a troca do transporte público pelo particular e a falta de infraestrutura das vias também são constantes problemas enfrentados. Esses problemas são agravados durante a realização de grandes eventos, tanto esportivos quanto de entretenimento, impactando diretamente no fluxo das grandes vias de acesso das cidades e na alta concentração de pessoas nos locais sede.

\section{Fatores de impacto na mobilidade urbana}

Para que haja a realização de um grande evento é necessário um espaço para sua realização. Neste sentido, há duas possibilidades: (1) espaço permanente e (2) espaço ocasional. Permanentes são espaços que apresentam como característica principal ter seu uso primordialmente destinado à realização de eventos, ainda que este espaço possa ser utilizado para outras atividades. Dentro dessa definição incluem-se estádios de futebol, foco de estudo neste trabalho.

Cidades ao redor do mundo utilizam eventos como forma de atrair uma maior visibilidade e um maior número de turistas, gerando, assim, receitas através do turismo. A realização do Grande Prêmio de Formula 1 é um exemplo de como o município pode ser beneficiado pela realização de um evento. A etapa disputada na capital paulista é capaz de atrair público de diversos lugares, sendo que 30,6\% do público presente residem em outro estado brasileiro e 6,3\% em outros países. Esta exposição causada à cidade 
de São Paulo por um evento dessa magnitude gera impactos econômicos estimados em aproximadamente U\$ 235 milhões por ano.

Conforme uma cidade se desenvolve, em geral apresenta um acréscimo em sua taxa de densidade demográfica e, como consequência, uma maior complexidade em sua rede de infraestrutura e, portanto, demanda um acréscimo da melhoria da gestão e do controle de eventos programados. Para que haja uma gestão eficaz, se faz necessária uma análise mais precisa de como os eventos podem influenciar em diversos aspectos observados pela população local e turistas. Uma parte do público utiliza transporte público como meio de locomoção para chegar até o local de realização do evento (Tabela 1). Assim, as vias na região ficam sobrecarregadas pela demanda extra e não planejada.

Tabela 1 - Meio de transporte utilizado para locomoção até o local do evento

\begin{tabular}{cccc}
\hline Meios de Transporte & Red Hot Chilli Peppers (2011) & David Guetta (2012) & Britney Spears (2011) \\
\hline Carro & $29 \%$ & $62 \%$ & $26 \%$ \\
Onibus & $27 \%$ & $11 \%$ & $34 \%$ \\
Trem & - & $1 \%$ & $5 \%$ \\
Metrô & $25 \%$ & $13,9 \%$ & $20 \%$ \\
A pé & $4 \%$ & $0,8 \%$ & $1 \%$ \\
Outros & $15 \%$ & $11,2 \%$ & $14 \%$ \\
\hline
\end{tabular}

Fonte: Observatório de Turismo e Eventos (2012).

Localidades que já apresentam uma grande concentração de pessoas e veículos são mais prejudicadas pela realização de um grande evento em seus arredores. Dentre as principais reclamações dos moradores na região estão: (1) bloqueio total ou parcial de vias da região; (2) aumento no número de veículos que se destinam à arena em dias de evento, interferindo na circulação nas principais vias de acesso; (3) estacionamento insuficiente para todos os carros que se destinam ao evento, ocasionando veículos estacionados sobre calçadas e em lugares proibidos.

Quando a reclamação e descontentamento da população são somados ao fato de que o trânsito é um problema reconhecido na cidade de São Paulo por afetar milhares de pessoas todos os dias, algumas medidas são tomadas para amenizar o efeito caótico da realização de grandes eventos em regiões de alto adensamento populacional. A autoridade de transporte urbano municipal monitorou as ruas da região do estádio do Morumbi durante a realização de um evento musical a fim de mostrar à população caminhos alternativos, áreas de estacionamento, opções de transporte coletivo, pontos de encontro e novos pontos de circulação devido ao fechamento de rotas para facilitar o fluxo naquela região. A partir disso, nota-se que a realização de grandes eventos pode perturbar uma região de modo a intensificar o congestionamento e desregular a rotina da população local.

A imprensa também divulga os impactos gerados pela realização dos eventos na região do Allianz Parque, onde são citadas as diversas vias fechadas na região (como a avenida Pompeia e rua Palestra Itália) que intensificam o trânsito apesar da atuação do poder público.

\section{Materiais e métodos}

\section{Variáveis da pesquisa}

As variáveis de uma pesquisa são definidas como parte integrante do fenômeno abordado, sendo elementos que possuem, de alguma forma, relação entre si, originando o objeto do estudo. Foram empregadas variáveis quantitativas, compondo a base de dados utilizada para a coleta e análise do acontecimento. Assim, ainda que proveniente de diversas fontes também coletadas, as variáveis principais e que impactam diretamente no projeto são as descritas na Tabela 2 abaixo. Essas variáveis estão relacionadas tanto aos dados obtidos para as linhas de ônibus quanto aos dados de rede social. 
Tabela 2 - Definição das variáveis utilizadas

\begin{tabular}{cc}
\hline Variáveis & Definição \\
\hline Localização & Posição exata do usuário no instante da coleta \\
geográfica & $\begin{array}{c}\text { Estruturação e segregação temporal dos dados coletados, sendo um referencial do } \\
\text { momento em que a coleta foi realizada } \\
\text { coleta }\end{array}$ \\
$\begin{array}{c}\text { Identificação do } \\
\text { provedor de dados }\end{array}$ & Análise de distinção da movimentação e comportamento do mesmo provedor dentre a \\
& área e o intervalo de coleta \\
\hline
\end{tabular}

Para a definição e filtragem da coleta de dados dos ônibus urbanos, além das três variáveis descritas anteriormente, também se fez necessária a definição das descrições das linhas e do sentido de movimentação dos ônibus que foram utilizados como fonte de coleta de informações.

Para a realização da pesquisa, foi necessário o estudo de uma grande quantidade de dados, com a geração de aproximadamente 43 milhões de iterações por dia de coleta. Sendo assim, foi utilizado o processo de data mining, no qual foi feita a extração de padrões e modelos sobre os dados obtidos por meio de servidores externos, para a análise posterior do objeto de estudo. A principal comunicação com os bancos de dados foi feita utilizando a linguagem R. O software escolhido para a programação foi a última versão RStudio. Sendo assim, houve a definição de datas que apresentem dados relevantes para a execução da pesquisa, ou seja, dados que efetivamente reportam a posição geográfica do elemento e ao mesmo tempo se encontram na área definida de estudo.

Por meio da análise dos dados públicos, feita utilizando a rede social Twitter, foi possível a aquisição de informações para posterior estudo, através de uma interface de programação que realizou a comunicação entre a aplicação e o desenvolvedor. Assim, foram necessários parâmetros de entrada com o intuito de padronizar e segmentar dados que sejam relevantes para a execução da pesquisa.

Um importante parâmetro é a área de interesse para obtenção de dados (bounding box), com o foco em observar a aglomeração e movimentação de pessoas em linhas de transporte público e em regiões periféricas à arena Allianz Parque. A ferramenta utilizada para a delimitação dessa região foi o OpenStreetMap.org na qual foi possível obter as coordenas geográficas das fronteiras definidas (Figura 3).

Foi possível, com os dados obtidos, a aplicação de diversos filtros para a segmentação de dados. Há informações referentes ao conteúdo da postagem, usuário, palavras-chave e localização geográfica. Porém, o único critério utilizado para a filtragem de dados nesta pesquisa foi a geolocalização deles, não havendo qualquer menção ou armazenagem a respeito de conteúdo, usuário ou plataforma.

A autoridade municipal de transporte público fornece em sua plataforma dados dos ônibus utilizados para transporte metropolitano na cidade de São Paulo, buscando prover as informações necessárias para desenvolvimento de aplicativos e estudos. 0 API de desenvolvimento, denominado pela companhia como Olho Vivo, monitora as coordenadas geográficas das linhas de ônibus da cidade. Assim, foram selecionadas linhas de ônibus que possuem ampla utilização por frequentadores do local e as que impactam diretamente na mobilidade urbana da região (Figura 4).

\section{Procedimento para análise de dados}

Com o local de estudo já definido, foi necessário realizar a análise do seu impacto logístico de modo que evidencie o reflexo destes fenômenos no entorno de sua região. Então, define-se o termo entorno como o conjunto formado por todas localidades que contornam um determinado local.

Para a definição da região de estudo, foram levadas em consideração as principais vias de acesso por apresentarem grande circulação de pessoas e automóveis e serem utilizadas como alternativa primária de locomoção até a região. 0 mapa de transporte público metropolitano também auxiliou na definição da área por este meio apresentar elevado impacto logístico, sendo também uma das principais alternativas de transporte para a locomoção até o local de evento, possuindo mais de 50 linhas de ônibus que chegam até a arena e a proximidade com estações de metrô. 


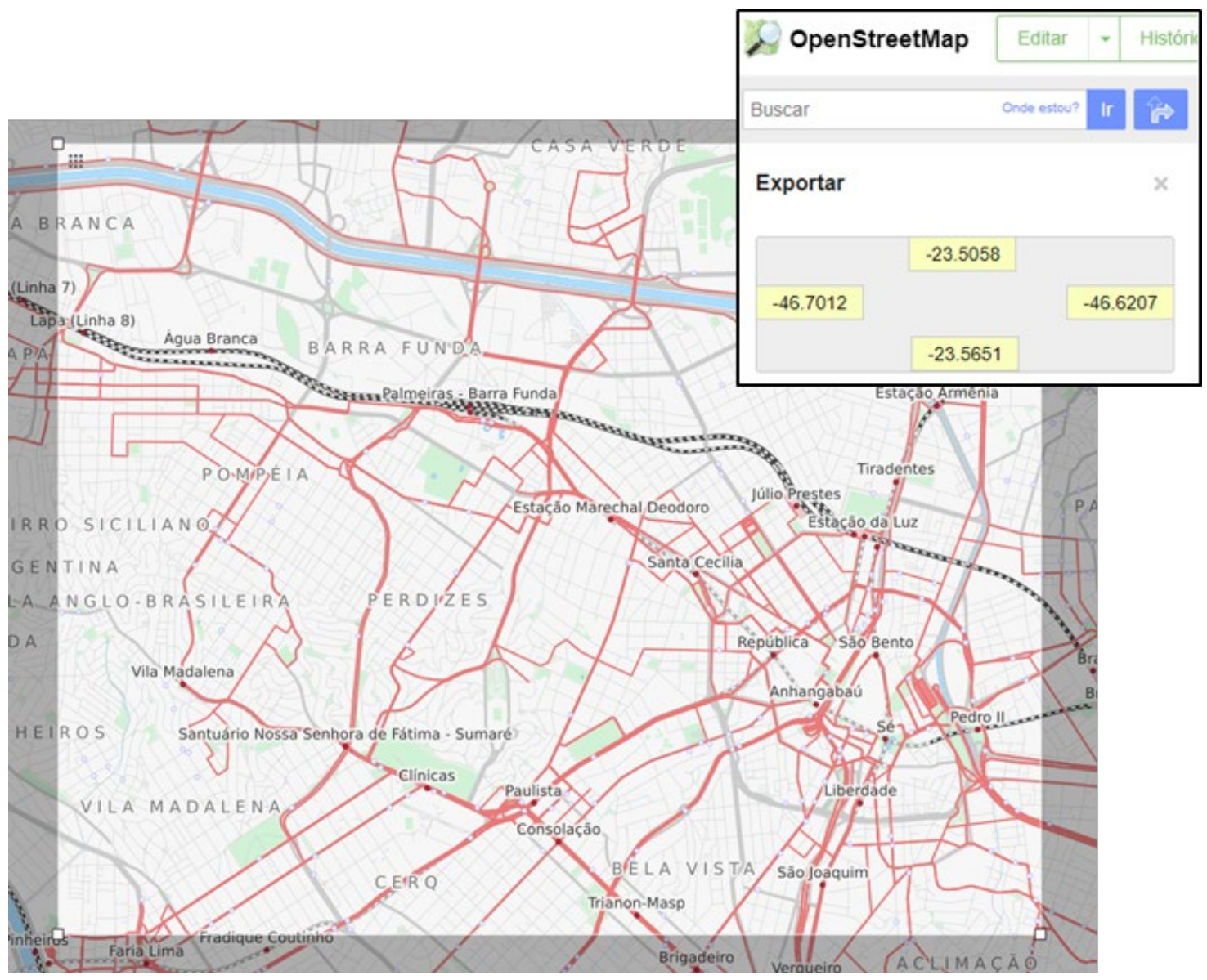

Figura 3 - Área de estudo com as coordenadas das fronteiras. Fonte: Os autores.

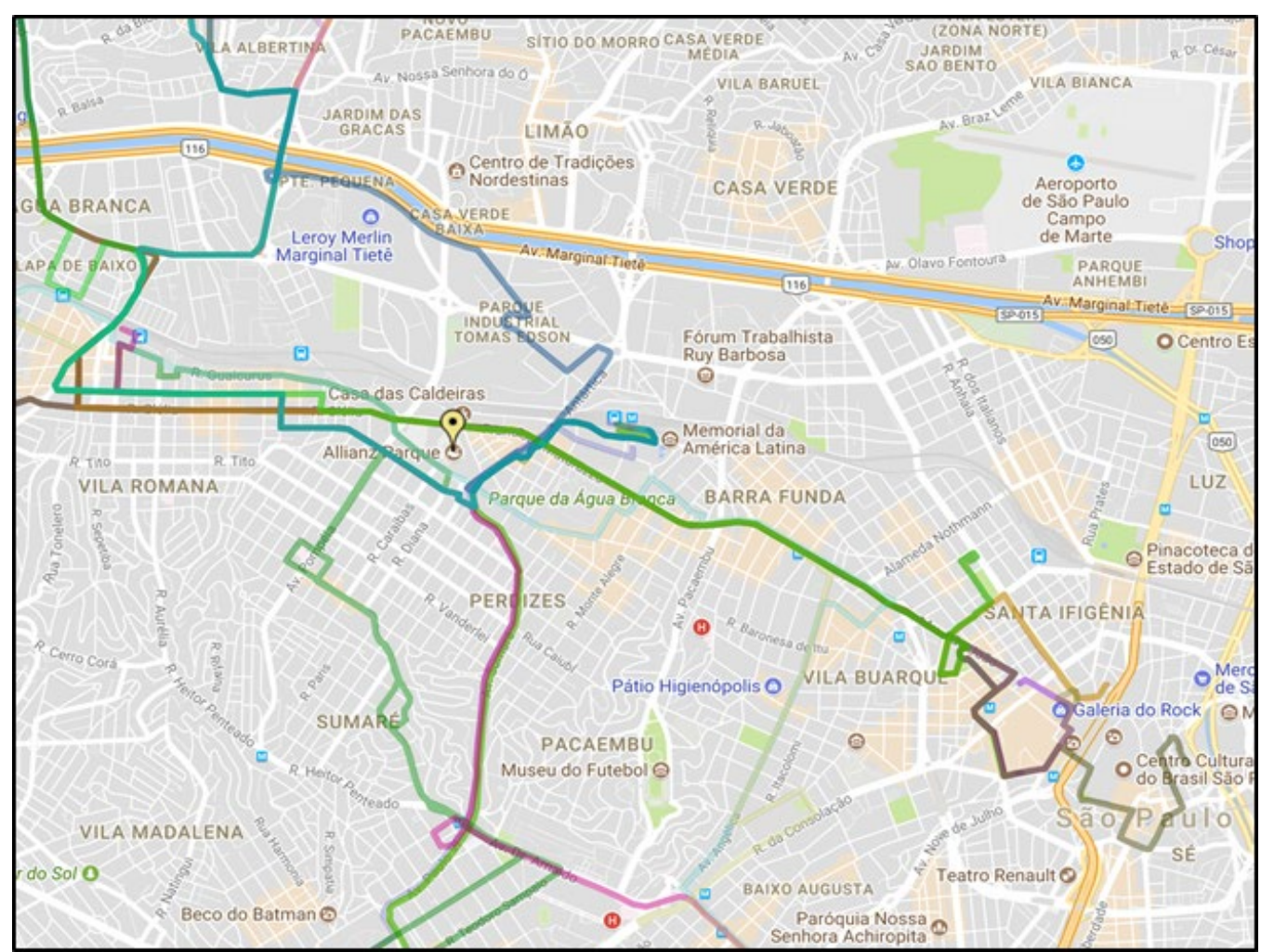

Figura 4 - Linhas de ônibus estudadas. Fonte: Os autores. 
De acordo com Camilo \& Silva (2009), a tarefa realizada para agrupamento de informações visa identificar e agrupar registros similares. Para a análise dos dados coletados do Twitter e da SPTRANS, a similaridade utilizada entre as informações obtidas foi a coordenada geográfica dos dados. A área foi dividida em três regiões, as quais foram delimitadas por informações de latitude e longitude (Figura 5).
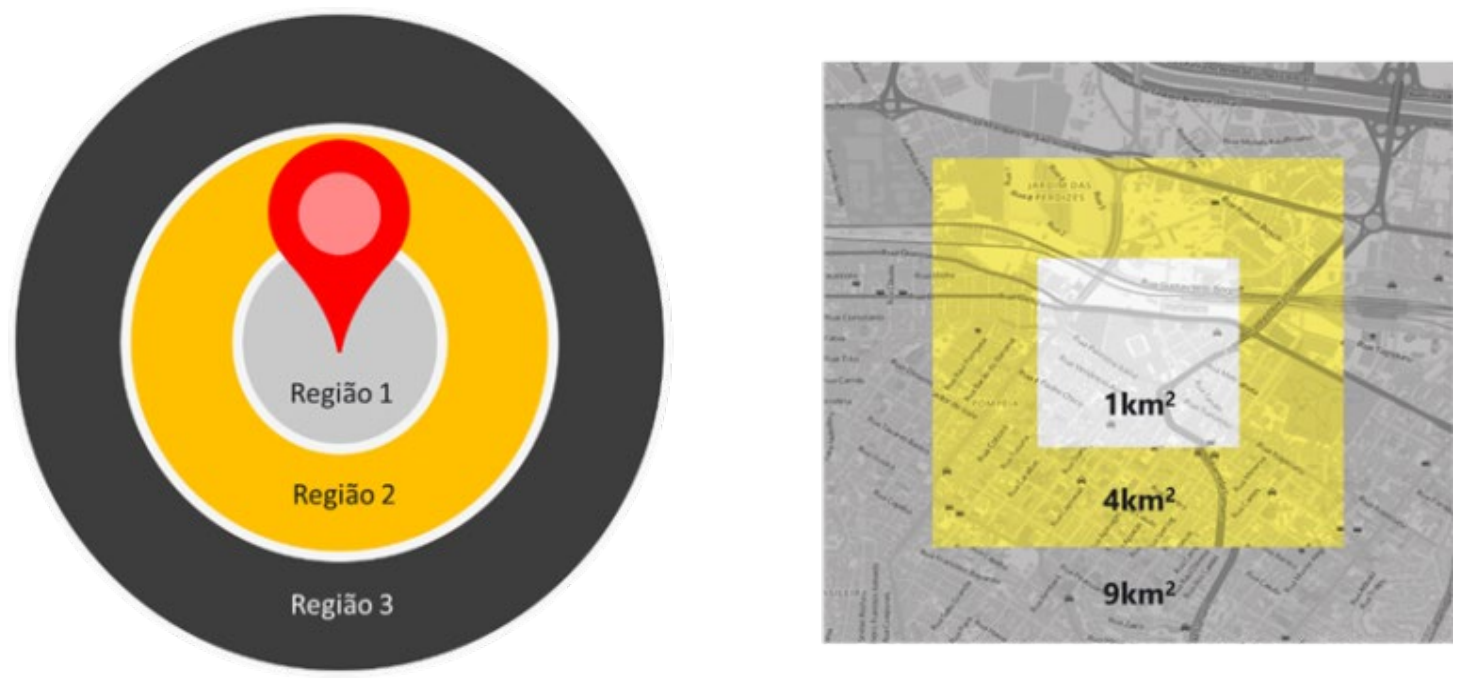

Figura 5 - Regiões delimitadas para estudo dos dados obtidos. Fonte: Os autores.

\section{Estrutura de dados}

Os dados foram obtidos pela comunicação entre a plataforma da empresa e o script em linguagem $\mathrm{R}$, possuindo uma estrutura base com uma extensão de arquivo JSON (JavaScript Object Notation). Com a obtenção dos dados da publicação realizada no Twitter, o estudo aponta como necessárias e relevantes apenas as informações referentes à data e posição geográfica do usuário no momento de sua publicação na rede social.

Por meio da utilização de outro script em $\mathrm{R}$, foi realizada a estruturação dos dados, isolando as variáveis supracitadas e remanejando a estrutura do arquivo, facilitando a sua visualização e posterior manipulação, permitindo que sejam realizadas análises pertinentes ao objetivo do projeto. Paralelamente, foi realizada a estruturação dos dados captados pela API do Olho Vivo, seguindo os mesmos critérios utilizados por Campos \& Cerqueira (2016) (Figura 6).

\section{Dados estruturados - Rede social}

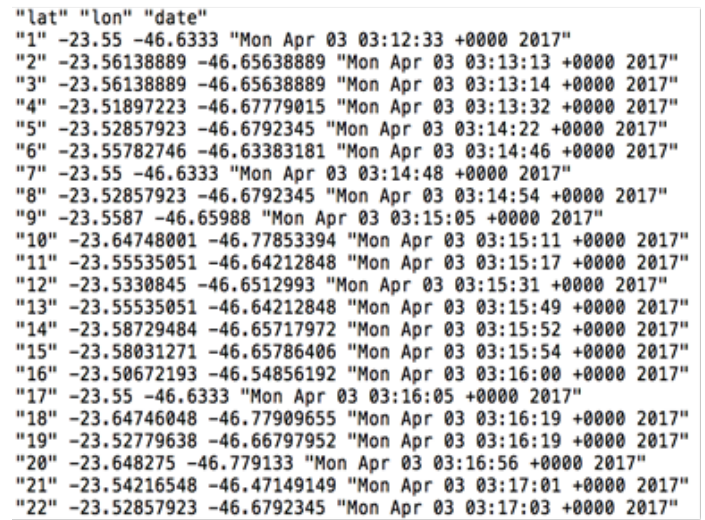

\section{Dados estruturados - Ônibus}

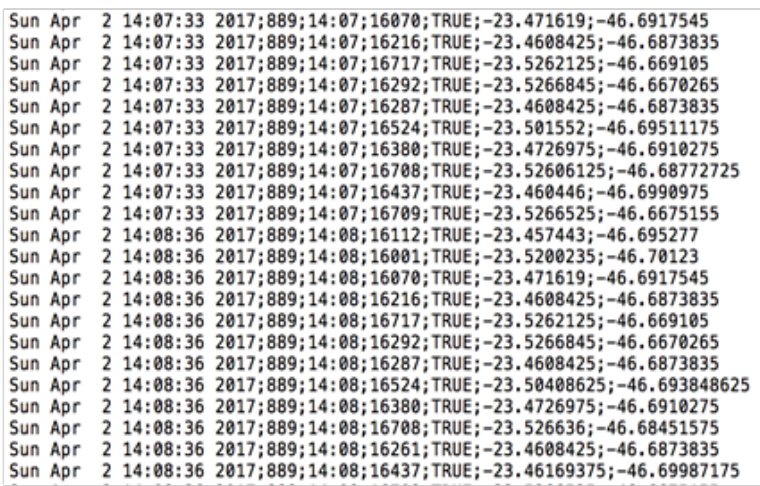

Figura 6 - Comparação de estruturas de dados. Fonte: Os autores. 
Com o banco de dados estruturado, foi necessário tratar todas as informações pertinentes ao estudo. Com as informações e dados provenientes das redes sociais, alguns dos filtros iniciais dessa seleção certificam que: (1) o dispositivo em que a publicação fora realizada possuía a capacidade de registrar sua localização geográfica no aplicativo durante a atividade; (2) o usuário tem conhecimento e permite acesso de sua posição durante o uso do aplicativo, nas preferências cadastrais da rede social; e (3) as informações de geolocalização são pertinentes à região e ao momento temporal do fenômeno em estudo (validação).

Já as capturas de dados dos ônibus foram passíveis principalmente de interferências físicas, que acabaram por comprometer o envio e recebimento das informações do veículo em determinados instantes devido à instabilidade do sinal da rede de emissão dos dados, além de barreiras físicas, como túneis, que também comprometem esse procedimento. Informações errôneas e incoerentes também podem ser emitidas pelo dispositivo de rastreamento do veículo, que devem ser analisadas de acordo com sua caracterização de origem: funcionamento momentâneo do equipamento ou incorreta utilização por parte do funcionário em trabalho.

0 envio de informações georreferenciadas dos ônibus foi realizado em um período constante de intervalo de tempo, ou seja, cada veículo iniciou seu envio de dados em um período distinto do dia de acordo com o início da sua jornada de trabalho. Essa particularidade resultou em uma necessidade de manter uma comunicação constante com o servidor da provedora, para que não ocorresse a perda de informações durante as capturas. A utilização desse método de coleta acabou gerando um volume grande de dados coletados, sendo, então, necessária a posterior identificação e remoção de informações duplicadas a fim de que não fosse comprometido o procedimento e base de dados dos posteriores cálculos.

Nakamuta \& Nakamura (2016) identificam como parte integrante do tratamento de dados a criação de campos de controle com o objetivo de enriquecer a análise, facilitar os filtros para que fossem realizadas as análises entre as variáveis do estudo.

Para avaliar as questões estudadas foi necessária a divisão em duas frentes: avaliação dos padrões dos dados coletados via Twitter (1) e cálculo dos indicadores a partir das informações do sistema Olho Vivo (2). Os dados foram segmentados dentro de cada um dos clusters pré-definidos. A partir da segregação e segmentação foi possível identificar padrões comportamentais no aumento do volume de publicações em cada região durante a realização de eventos.

Contribuindo para essa análise dos padrões, a rotulação do número total de publicações diárias a cada hora. Os dados coletados foram agrupados a partir de zero segundo do início da hora até o último segundo dela (e.g. das 02:00:00 até 02:59:59), facilitando a análise do comportamento das amostras ao decorrer do dia avaliado. Os indicadores desenvolvidos por Campos \& Cerqueira (2016) baseiam-se na fórmula de Haversine. Assim, consideram a curvatura do planeta Terra para o cálculo da distância entre dois determinados pontos geográficos. Para análise de impacto nas regiões definidas, foi selecionado o indicador de velocidade média, que apresenta a relação entre a distância percorrida por um ônibus em seu trajeto com um período de tempo efetivo para realizá-lo.

Com as informações disponíveis de todas as linhas de transporte estudadas, foi necessário segregar as informações respectivas a cada um dos ônibus pertencentes as elas. Assim, primeiramente, foi necessário também realizar o agrupamento das informações de acordo com o horário de coleta, porém com um intervalo de 30 minutos - menor que o agrupamento das publicações, devido a um volume muito superior de dados, volume esse que permitiu uma análise mais detalhada da variação da velocidade média durante o dia. 0 cálculo da velocidade média de cada ônibus foi realizado a partir da divisão da sua distância percorrida entre dois momentos de coleta pela diferença entre os tempos de cada iteração. De modo a contornar as inconsistências de envios de dados, foi utilizado o método de regressão linear para interpolar a velocidade média entre os últimos pontos que efetivamente possuem dados consistentes. Existem diversos estudos que propõem formas diferentes de realizar esta aproximação, porém este foi escolhido devido à sua simplicidade e pelo fato de este item, embora importante, não ser o foco do presente estudo. 
Contribuindo para a análise dos fenômenos estudados, foram criados dois indicadores: (1) variação de velocidade máxima ( $\Delta$ Tmáx); e (2) variação média de velocidade ( $\overline{\Delta T}$ ).

A variação de velocidade máxima trata-se da maior variação entre a velocidade média das linhas estudadas durante um dia comum e suas velocidades médias em um dia com algum evento na arena. Já a variação média de velocidade foi calculada de modo similar, porém fora realizada a média ponderada das variações dessas velocidades durante todo o período de duração do evento. Esses indicadores têm por finalidade demonstrar e quantificar os impactos de intensidade ( $\Delta$ Tmáx) e persistência $(\overline{\Delta T})$ na mobilidade da região gerados pelo evento em estudo, sempre relacionando com uma base comparativa de uma média de 10 dias comuns sem eventos (Figura 7).
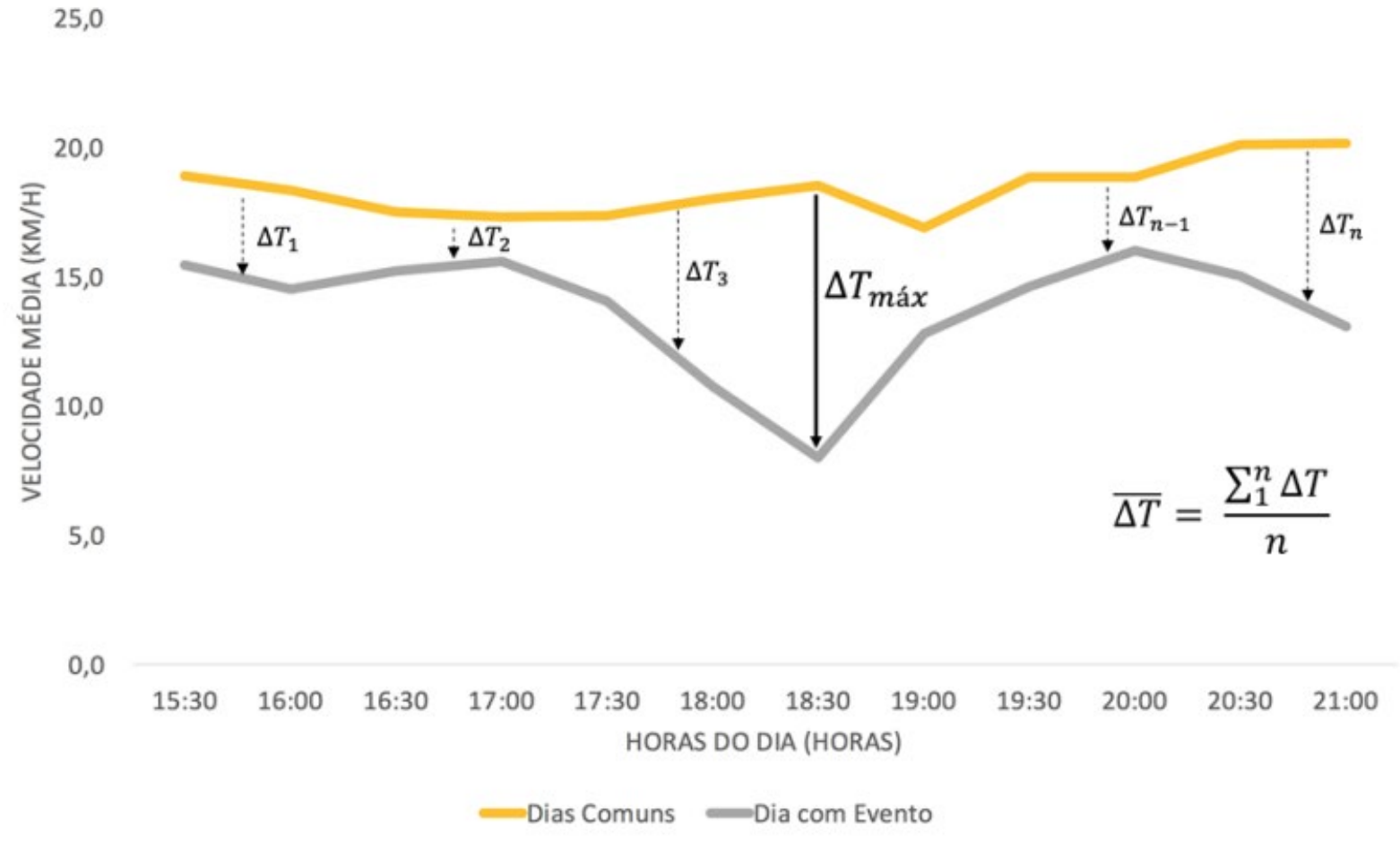

Figura 7 - Cálculo de indicadores. Fonte: Os autores.

Ambas análises de redes sociais e de transporte público contribuem para que haja uma comparação do comportamento e do impacto na mobilidade urbana da região entre dias rotineiros com outros que obtiveram a realização de algum evento no Allianz Parque.

\section{Resultados e discussão}

O estudo foi feito na região de Água Branca em São Paulo, na arena Allianz Parque — sede de grandes eventos. A partir da determinação da área de análise, foi definido que seriam coletados dados das linhas de ônibus que passam ao redor da região e, também, das redes sociais, mais precisamente o Twitter. Na área de estudo de $9 \mathrm{~km} 2$ foram consideradas 44 linhas de ônibus para obtenção de dados, dentre elas estão, por exemplo, as linhas 177Y-10 - Pinheiros, 8545-10 - Barra Funda e 856R-21 - Socorro.

Os dados obtidos dessas coletas foram tratados e analisados a fim de entender o comportamento do trânsito e dos pedestres nessa região. Com isso, foi possível realizar comparações indicando esses comportamentos e confrontando os dias de eventos com uma média de dias normais. A partir dessa comparação foram computados dois indicadores que medem a persistência e intensidade de cada evento, mostrados na Tabela 3. Com os indicadores foi possível quantificar o impacto dos grandes eventos na mobilidade urbana. 
Tabela 3 - Eventos

\begin{tabular}{|c|c|c|c|c|c|c|}
\hline \multirow{2}{*}{ Evento } & \multicolumn{4}{|c|}{ Delta Máximo ( $\left.\Delta T_{\text {máx }}\right)$} & \multicolumn{2}{|c|}{ Delta Médio $(\overline{\Delta T})$} \\
\hline & Região 1 & Região 2 & Região 3 & Região 1 & Região 2 & Região 3 \\
\hline Justin Bieber - 02/04/2017 & 15,1 & 13,88 & 4,13 & 7,34 & 5,16 & $-0,01$ \\
\hline Bon Jovi - 23/09/2017 & 15,89 & 7,57 & 3,37 & 5,50 & 3,67 & 0,23 \\
\hline Brasil vs Chile - 10/10/2017 & 9,68 & 6,81 & 3,73 & 5,39 & 1,99 & 1,29 \\
\hline Paul McCartney - 15/10/2017 & 4,01 & 1,81 & 0,02 & 0,05 & $-1,27$ & $-1,83$ \\
\hline John Mayer - 18/10/2017 & 9,91 & 4,60 & 1,76 & 3,82 & 1,47 & $-0,43$ \\
\hline
\end{tabular}

Fonte: Os autores.

Para demonstração dos resultados foram apresentadas cinco análises de eventos que ocorreram no Allianz Parque entre abril e outubro de 2017. Desses cinco eventos, quatro são de caráter musical e um esportivo. Foram coletados também dias comuns para a obtenção de informações de velocidade média e publicações em redes sociais para critérios comparativos.

As análises comparativas entre dia normal e dia com evento mostram o comportamento do trânsito bem como a quantidade de publicações da região perto dos horários de entrada e saída do evento. Esses horários variam de um dia para o outro, de acordo com a abertura dos portões da arena e com as vias secundárias que podem ou não ser fechadas dependendo do evento que será realizado.

0 evento musical ocorreu no dia 02 de abril de 2017 (domingo), tendo início às $20 \mathrm{~h} 00$ e término às 23h00. Por se tratar de um domingo, o trânsito dessa região não deveria ser intenso como em dias de semana, porém apresentou uma conduta diferente por se tratar de um dia com evento e os resultados podem ser observados na Figura 8.

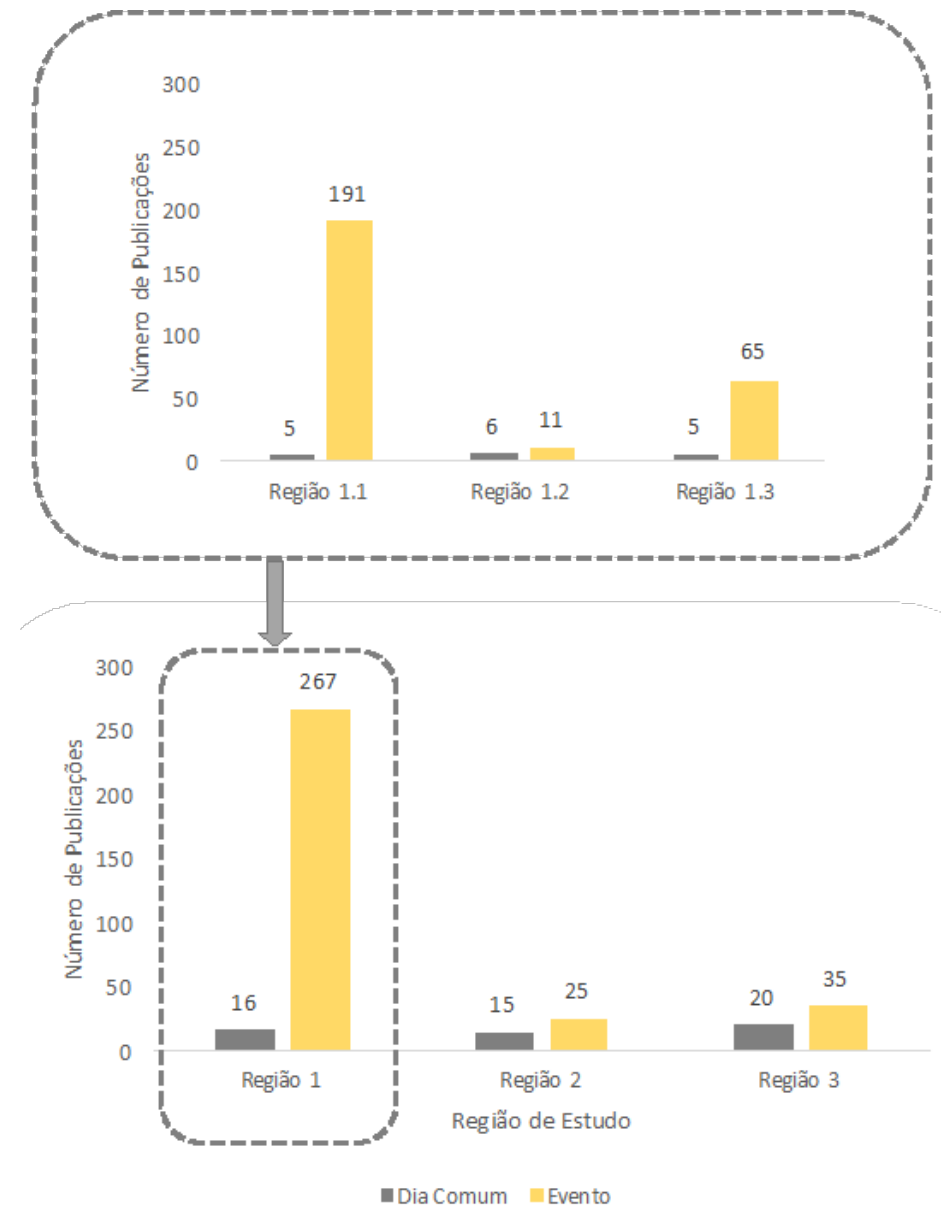

Figura 8 - Publicações do Twitter no show do Justin Bieber. Fonte: Os autores. 
Com a análise das publicações de redes sociais durante esse evento, foi possível observar maior concentração de pessoas na região 1 em comparação com a média de dias normais. Segregando essa região para estudo, nota-se que o maior número de publicações se deu, de fato, na região 1.1, que representa exclusivamente o Allianz Parque. Nesse evento em específico, houve dois comportamentos atípicos: volume de publicações muito maior do que os outros eventos estudados e uma quantidade considerável de publicações na região 1.3. Uma das hipóteses para justificar essa abundância de dados foi o fato de que o público-alvo do evento era em sua maioria composto por jovens e, consequentemente, utilizam mais as redes sociais.

Com a análise das linhas de ônibus estudadas durante o período do evento, foi possível identificar uma queda da velocidade média, principalmente perto do horário de término, como pode ser observado pela análise gráfica das três regiões, em conjunto com os indicadores presentes na Tabela 3. 0 gráfico a seguir demonstra a diferença negativa entre a velocidade média de dias comuns e do dia do evento, ou seja, as áreas em destaque mostram a dimensão do impacto desses eventos nos respectivos horários (Figura 9).

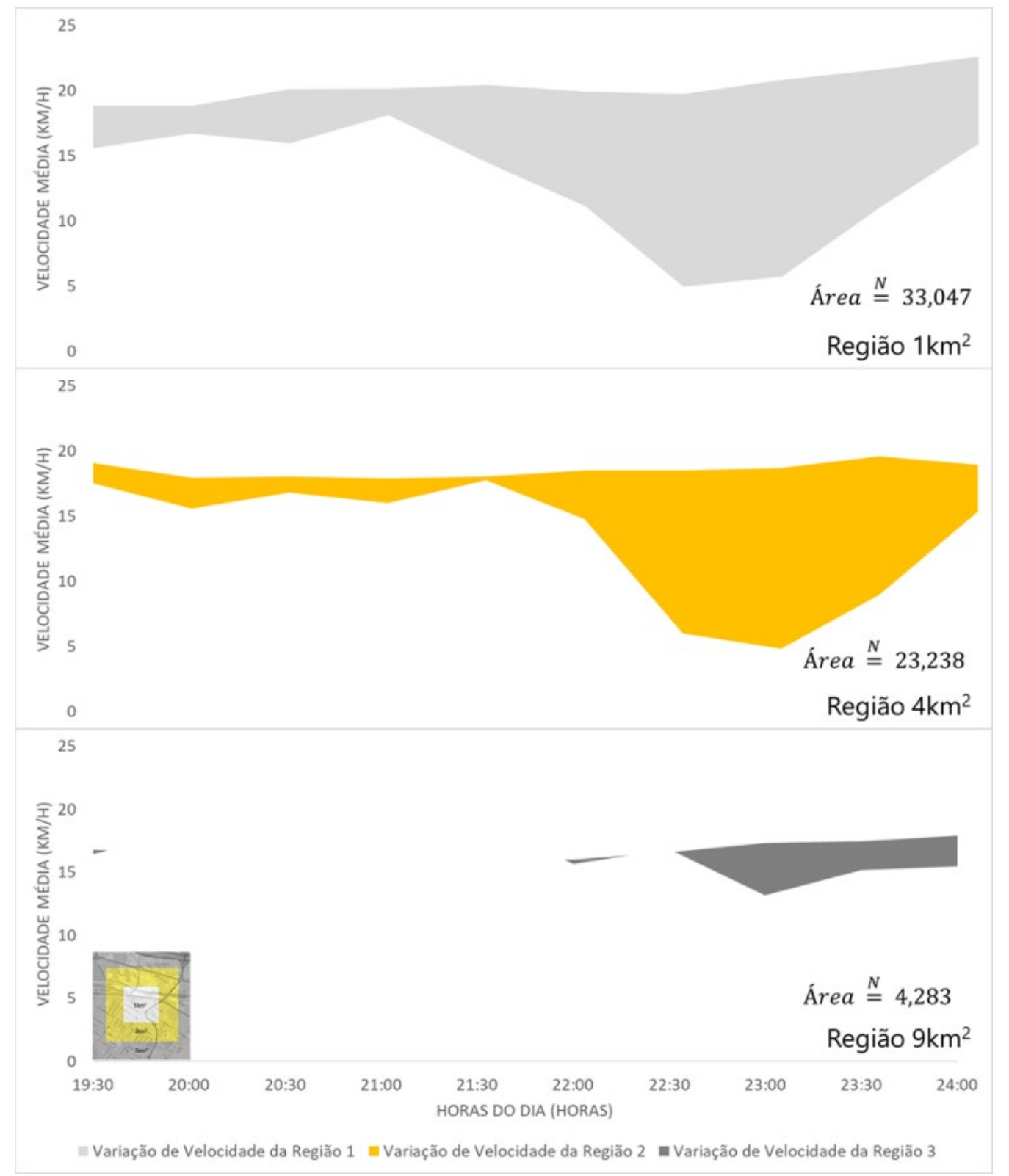

Figura 9 - Gráfico comparativo da velocidade de um dia comum com o dia do show do Justin Bieber em cada uma das regiões. Fonte: Os autores. 
No gráfico acima, quanto maior a área aparente, maior a variação da velocidade, uma vez que a linha superior indica a velocidade padrão no caso de ausência de evento. Ao quantificar essas áreas obtidas, nota-se a variação conforme a região de análise se distancia do epicentro do show. Esses valores foram obtidos a partir de uma análise gráfica dos resultados já calculados. A partir das áreas encontradas é possível analisar com precisão o impacto no dia de evento (Tabela 4).

Tabela 4 - Quantificação das diferenças de velocidade dos gráficos comparativos do evento Justin Bieber

\begin{tabular}{cc}
\hline Regiões & Área calculada \\
\hline Região 1 & 33,047 \\
Região 2 & 23,238 \\
Região 3 & 4,283 \\
\hline
\end{tabular}

\section{Análise de resultados}

Com a análise de mais de 20 dias do ano de 2017, utilizando uma base comparativa com média de observação de 10 dias sem eventos, notou-se uma aglomeração muito pontual na primeira região de análise periférica de $1 \mathrm{~km}^{2}$ da arena, além de contar com um volume de dados de redes sociais não tão expressivo (número médio de quatro publicações por hora).

Tal fato contribuiu para a abordagem da metodologia de análise de todas essas informações, com a finalidade de compreender e segmentar melhor esses dados e a região. Com a subdivisão dessa região em três outras menores, foi possível isolar qualquer manifestação recorrente no Allianz Parque dos demais fatores que poderiam ser potenciais impactantes e, consequentemente, comprometer e influenciar a geração das análises quantitativas desses dados. Adicionalmente, foi observada uma concentração pontual de usuários da rede social na arena durante o evento, que, mesmo sendo diferente dos demais dias rotineiros da cidade, possuiu uma variação significante somente na região mais próxima à sede do evento, conforme indica o gráfico da Figura 10.

Paralelamente, os dados coletados dos ônibus também foram referenciados à mesma base de dias que foram utilizados na análise das publicações da rede social. Com o cálculo dos indicadores de velocidade média de cada um dos dias, tanto comuns quanto com eventos. Desta forma, foi possível visualizar o comportamento das linhas de estudo durante todo o instante do dia.

Utilizando e replicando o método de análise para cada um dos dias coletados, foram realizados o agrupamento e o cálculo de uma média ponderada entre dez desses dias que mostram um comportamento de variação semelhante, por retratarem dias comuns sem algum evento na região da arena. Com o gráfico do comportamento comum médio dos transportes na região de estudo, foi possível identificar um padrão semelhante entre os dias abordados: todos os dias apresentam um aumento gradativo de sua velocidade média ao fim do dia, após a queda mais acentuada do dia, que acaba ocorrendo no período das 18:30h às 19:00h (Figura 10).

Em dias com eventos nota-se uma queda na velocidade média nos momentos que precedem o início e o término dele e neste intervalo há um aumento de velocidade, mas ainda sendo abaixo da média de dias comuns. A queda da velocidade no começo dos eventos nem sempre foi expressiva, porém sempre há uma queda considerável após o término, visto que o público se concentra em um mesmo horário para evacuação do local.

A partir disso, observa-se que existem fatores que impactam diretamente na variação das velocidades médias e, consequentemente, no congestionamento, influenciando na mobilidade urbana da região. Horário de abertura dos portões, o dia da semana em que ocorre o evento, fatores climáticos e naturais e o próprio horário do evento são exemplos de fatores que interferem diretamente no local de estudo. Esse fato foi representado nos indicadores de intensidade e persistência que, por sua vez, podem mostrar a correlação entre esses mesmos fatores. 


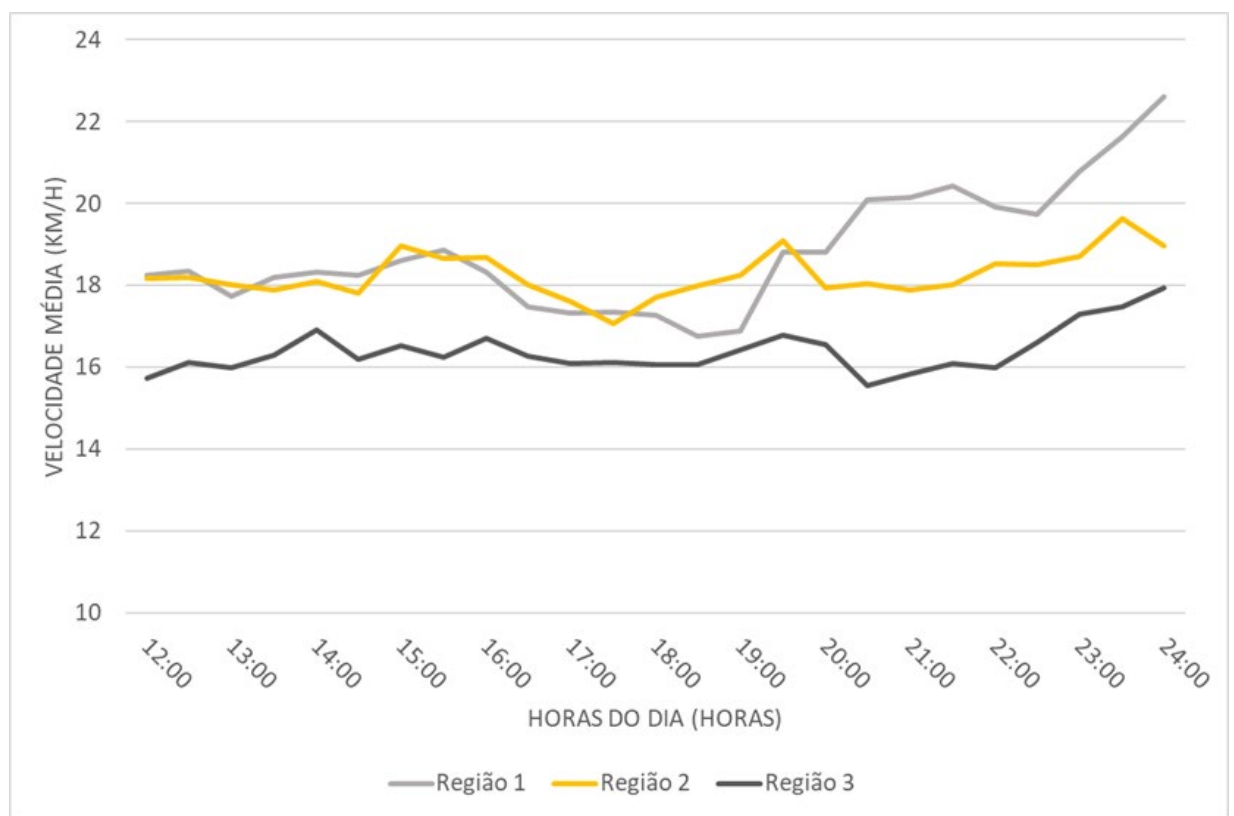

Figura 10 - Comportamento da velocidade média de 10 dias comuns nas regiões estudadas. Fonte: Os autores.

\section{Conclusão}

Como o objetivo da coleta dos dados da rede social visou analisar a aglomeração de pessoas e como esta aglomeração se comportou, este objetivo foi atingido, uma vez que foi identificado durante o período dos eventos um número de publicações muito maior do que em dias sem evento. Esse fator pode, ainda, ser salientado na separação por regiões, indicando que a concentração está literalmente localizada na arena Allianz Parque.

As coletas de dados do transporte público puderam, também, quantificar o impacto de grandes eventos na mobilidade urbana da região de estudo. Somados aos dados coletados, foi possível desenvolver indicadores e um método de análise.

Além disso, através das inúmeras informações trabalhadas durante o estudo, incluindo transposições gráficas desses elementos, foi possível notar que a necessidade de um estudo sobre esse tema é de extrema relevância para a cidade de São Paulo. Essa relevância se dá uma vez que os moradores da região sofrem diariamente com o trânsito e quando há a ocorrência de eventos, isso tende a piorar.

Adicionalmente, durante o desenvolvimento do trabalho, o baixo volume de dados obtidos pelo Twitter indicou que essa rede social vem se tornando atualmente pouco utilizada. Percebeu-se, então, que com todos os dados coletados, existe a capacidade e possibilidade de identificar pontos críticos de concentração de pessoas que, durante os estudos, comprovaram ser pontos de ocorrência de algum evento.

Nota-se que cada evento possui uma característica única de impactar a mobilidade da região. Esse grau pode ser definido de formas diferentes, principalmente quanto à intensidade e persistência, resultados dos indicadores calculados a partir da variação de velocidade em dias comuns comparados aos dias com eventos.

Com a quantificação dos reflexos de cada evento, observa-se que alguns são mais intensos e podem impactar a determinada região por um maior intervalo de tempo. Em contrapartida, existem eventos que não interferem tanto no local, ou seja, não são tão influentes nesse impacto logístico. Porém, o comportamento típico de todos os eventos analisados foi a redução da intensidade de sua influência no impacto do evento em regiões mais afastadas do Allianz Parque.

Como sugestão para trabalhos futuros, é possível fazer análise e coleta de dados provenientes de outras redes sociais, como Facebook e Instagram, que possuem maior volume de publicações 
georreferenciadas. Além disso, com o método de quantificação já estabelecido, pode-se ampliar a região de estudo, realizar a análise de outros fatores influenciadores no trânsito (chuva, feriado, entre outros), estudo de outras regiões na cidade de São Paulo e/ou cenários similares.

\section{Referências}

Camilo, C. O., \& Silva, J. C. D. (2009). Mineração de dados: conceitos, tarefas, métodos e ferramentas (pp. 1-29). Goiânia: Universidade Federal de Goiás.

Campos, B., \& Cerqueira, F. (2016). Proposta de um método de análise de sistemas de transporte público. São Caetano do Sul: Instituto Mauá de Tecnologia.

Leite, C. (2017). São Paulo, megacidade e redesenvolvimento sustentável: uma estratégia propositiva. urbe. Revista Brasileira de Gestão Urbana, 2(1), 117-126.

Mendonça, No., W. L., \& Kneib, É. C. (2016). Centralidades urbanas e oferta de transporte público coletivo em Goiânia-GO, 2014. Transportes, 24(1), 42-50. http://dx.doi.org/10.14295/transportes.v24i1.916.

Molina, M. J., \& Molina, L. T. (2004). Megacities and atmospheric pollution. Journal of the Air \& Waste Management Association, 54(6), 644-680. http://dx.doi.org/10.1080/10473289.2004.10470936. PMid:15242147.

Nakamuta, F., \& Nakamura, M. (2016). Estudo da mobilidade urbana de pedestres em uma grande cidade usando big data. São Caetano do Sul: Instituto Mauá de Tecnologia.

Observatório de Turismo e Eventos. (2012). Relatório evento: Britney Spears. Recuperado em 12 de maio de 2017, de http://www.observatoriodoturismo.com.br/pdf/RELATORIO_SHOW_BRITNEY.pdf

Rau, S. L. (2012). Sistema cicloviário e suas potencialidades de desenvolvimento: o caso de Pelotas/RS (Dissertação de mestrado). Universidade Federal de Pelotas, Pelotas.

Reddy, B. S., \& Balachandra, P. (2010). Dynamics of urban mobility: a comparative analysis of megacities of India. Mumbai: Indira Gandhi Institute of Development Research.

Statista. (2014). The World's Megacities Are Set for Major Growth. Recuperado em 3 de maio de 2017, de https://www.statista.com/chart/1826/population-growth-in-the-worlds-megacities/.

Editor: Fábio Duarte

Recebido: Set. 17, 2019

Aprovado: Jun. 17, 2020 